\title{
DENITROGENATION BY ADSORPTION OF PYRIDINE ON NI/SUPPORT ADSORBENTS
}

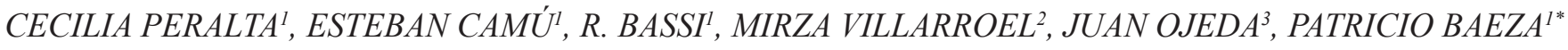

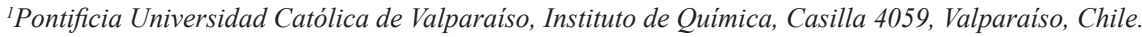 \\ ${ }^{2}$ Universidad de Santiago de Chile, Facultad de Química y Biología, Casilla 40, Correo 33, Santiago, Chile. \\ ${ }^{3}$ Universidad de Valparaíso, Facultad de Farmacia, Casilla 5001, Valparaíso, Chile.
}

\begin{abstract}
In this work we have carried out the adsorption of pyridine using three different supports (activated carbon, $\mathrm{SiO}_{2}$ and $\gamma$ - $\mathrm{Al}_{2} \mathrm{O}_{3}$ ). $\mathrm{After}_{\mathrm{f}}$ choosing the best support, due to its higher adsorption capacity, we have impregnated the support with nickel at three different concentrations $(2,4$ and $6 \%$ w/w) by wet impregnation to study the adsorption of pyridine by $\pi$-complexation. All the samples (supports and adsorbents) were characterized by $\mathrm{N}_{2}$ adsorption-desorption by the BET method and electrophoretic migration. The experimental results, for the three different supports, show that the adsorption capacity is better for $\gamma$ - $\mathrm{Al}_{2} \mathrm{O}_{3}$, due to its higher isoelectric point. With the incorporation of nickel, no better adsorption capacities are observed, due that the nickel incorporation diminish the zero point charges of the adsorbents.
\end{abstract}

Keywords: Adsorption, denitrogenation, nickel, pyridine.

\section{INTRODUCTION}

Crude oil is the largest and most widely used source of energy in the world and projections assure that this will continue until at least 2050. Overexploitation of existing fields, has led to crude oils known as "Barrel Fund", composed of high molecular weight hydrocarbons which are of lower quality, as they are much heavier and therefore difficult to purify in the petroleum refining industry. The combustion of petroleum containing nitrogen compounds emits NOx into the atmosphere, which directly contributes to the production of acid rain and Photochemical Smog. Therefore, environmental regulations are becoming more stringent with regard to the maximum level of nitrogen molecules that petroleum may contain; this has caused refiners to seek new methods that allow them to eliminate nitrogenous molecules. These nitrogen containing molecules are more resistant to the existing process used in the refining industry to remove them. This hydrotreating process is called hydrodenitrogenation (HDN) and it operates at elevated temperatures and pressures, which are efficient in removing simple nitrogen molecules, but not for the removal of "refractory molecules". Nitrogenous compounds present in the petroleum may vary depending on the origin of the oil field. Despite this, the predominant compounds consist of substituted pyrrole and pyridine, which containing aromatic rings of 5 and 6 members, respectively ${ }^{1}$. At present, petroleum is composed of alkylated nitrogenous organic molecules, on some part of the aromatic ring, which are refractory to the HDN process ${ }^{2,3}$.

It should be noted that the catalysts used in petroleum refining for the HDN reaction are $\mathrm{Ni}-\mathrm{Mo} / \gamma-\mathrm{Al}_{2} \mathrm{O}_{3}$ or $\mathrm{Co}-\mathrm{Mo} / \gamma-\mathrm{Al}_{2} \mathrm{O}_{3}$ catalysts, where $\mathrm{Co}$ and $\mathrm{Ni}$ promote the activity of $\mathrm{MoS}_{2}$, but an important point is that these catalysts are also active in the hydrodesulfurization (HDS) reaction, and furthermore, both reactions are carried out in the same reactor with an unique catalyst, and in the case of nitrogen containing compounds, their removal is highly recommended to ensure successful HDS. It is these nitrogen compounds that inhibit HDS and other hydrotreating processes, because these molecules are preferentially adsorbed at the same catalytic site ${ }^{3,4}$.

The most common methods for the removal of nitrogen compounds are biological degradation ${ }^{5-7}$, photocatalysis $^{8}$, ozonation ${ }^{9}$, membrane separation ${ }^{10}$, and adsorption ${ }^{11-14}$. It is interesting to find and to study new alternatives to remove or separate the nitrogenous compounds from petroleum in order to reduce the NOx generated in the combustion of petroleum and diminish the magnitude of the inhibitory effect of these molecules in other petroleum refining processes; implementing new purification processes that are more environmentally friendly.

The use of adsorption to selectively remove the nitrogen compounds by a $\pi$-complexation mechanism under ambient conditions is an excellent option, the metallic cation can form the usual $\sigma$ bonds with their s-orbitals, while their d-orbitals can back-donate electron density to the antibonding $\pi$-orbitals of the nitrogen rings in organic nitrogen compounds. The metals that can form strong $\pi$-complexation bonding are those that possess empty s-orbitals and the necessary electron density available at the d-orbitals for back donation, thereby, $\mathrm{Cu}^{1+}, \mathrm{Ag}^{1+}$ and $\mathrm{Ni}^{2+}$ are good options; within the above mentioned cations, $\mathrm{Ni}^{2+}$ in oxidized state is simply obtained by a calcination process ${ }^{15-17}$. In previous studies where the adsorption of 4,6-DMDBT was studied on activated carbon impregnated with different metals of the first transition series ${ }^{18}$, it was found that the adsorption capacity of the materials depends on the nature of the metal which acts as active site in the $\pi$ type adsorption and we observed a volcano type curve with a maximum in $\mathrm{Ni}$ with oxidation state +2 .

It's well known, that activated carbon has excellent adsorption properties, due mainly to its high specific area ${ }^{19}$, but also, other different materials have been investigated as adsorbents, in the case of alumina, It has been used in the removal of organic compounds from aqueous solutions ${ }^{20}$ as well as in removing phosphates ${ }^{21}$ and heavy metals $\mathrm{s}^{22,23}$, these good adsorption properties are due mainly to specific area of the alumina and the amount of hydroxyl groups present on its surface. Silica has been studied in the denitrogenation by adsorption of a raw diesel ${ }^{24}$, and light gas oil $(\mathrm{LGO})^{25}$, among other adsorption studie $^{26-27}$, so, it will be interesting to study which of the three support possess a better adsorption performance, to impregnate it with nickel at 2, 4, 6\% w/w and evaluate the $\pi$-complexation mechanism, using pyridine as a model molecule.

\section{EXPERIMENTAL}

\subsection{Preparation of the adsorbent}

The supports studied were: $\mathrm{SiO}_{2}, \gamma-\mathrm{Al}_{2} \mathrm{O}_{3}$ and activated carbon $\left(\mathrm{C}_{\text {act }}\right)$, these commercial supports were used in a particle size between 120 and 270 mesh, this samples were dried at $100{ }^{\circ} \mathrm{C}$ for 2 hours in a muffle to remove traces of water.

The adsorbents were prepared by dry impregnation of the best support, obtained in support adsorptions studies, with an aqueous solution of $\mathrm{Ni}\left(\mathrm{NO}_{3}\right)_{2} \times 6 \mathrm{H}_{2} \mathrm{O}$, containing the required amount of precursor salt to render a nominal concentrations of $\mathrm{Ni}$ at 2,4 or $6 \% \mathrm{w} / \mathrm{w}$. After impregnation of the supports, the adsorbents were dried at $100{ }^{\circ} \mathrm{C}$ for $12 \mathrm{~h}$, and then calcined at 300 ${ }^{\circ} \mathrm{C}$ for $3 \mathrm{~h}$ in a muffle furnace.

\subsection{Samples characterization}

For specific area (BET) determination $0.2-0.4 \mathrm{~g}$ of each sample were taken, which were degassed at $120^{\circ} \mathrm{C}$ for 18 hours, reaching a final pressure of $1 \times 10^{-3} \mathrm{mmHg}$. Subsequently, the analysis was performed within a glass slide at $-196{ }^{\circ} \mathrm{C}$ using a Micromeritics ASAP-2010 apparatus for volumetric nitrogen adsorption-desorption.

Zeta potential measurements by electrophoretic migration were performed on a Zeta Meter, model 3.0, provided with an automatic transfer unit sample. In each measurement is used approximately $30 \mathrm{mg}$ of the sample suspended in $300 \mathrm{~mL}$ of $\mathrm{KCl}$ solution $1 \times 10^{-3} \mathrm{M}$. Between each point, the $\mathrm{pH}$ was adjusted with $0.1 \mathrm{M} \mathrm{KOH}$ or $\mathrm{HCl}$ as required.

\subsection{Adsorption experiments}

Adsorption experiments were performed in a vertical Pyrex reactor equipped with a supporting glass porous disk. A bed of $\sim 500$ milligrams of different adsorbents was placed in the reactor. Prior to the determination of the adsorption capacity $\left(\mathrm{A}_{c}\right)$, a process was performed for each support and adsorbent, with a $20 \mathrm{~mL} \mathrm{~min}^{-1}$ flow of pure $\mathrm{Ar}$ at $200^{\circ} \mathrm{C}$ for $30 \mathrm{~min}$ and 
subsequent cooling. Finally, the temperature was lowered again to ambient

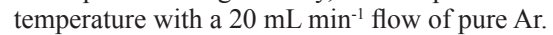

For the adsorption experiments, the liquid flow was driven into the reactor by means of a variable flow peristaltic mini-pump. The experiment was performed using an artificial mixture of $500 \mathrm{ppmv}$ of pyridine in isooctane at a feed rate of $\sim 0.5 \mathrm{~mL} \mathrm{~min}^{-1}$. Samples were collected every $5 \mathrm{~min}$, until saturation of the adsorbent was achieved; the total time and number of samples depended on the amount of adsorbent and its adsorption capacity.

The samples were analyzed by gas chromatography with a flame ionization detector (GC- FID), using a Shimadzu GC-2010 equipped with an SPB-5 capillary column (L 30m, I.D. $0.25 \mathrm{~mm}$, Film $0.25 \mathrm{~mm}$ ), and the following conditions: detector at $250{ }^{\circ} \mathrm{C}$, injector at $150^{\circ} \mathrm{C}$, and carrier flow, $15 \mathrm{~mL} \mathrm{~min}^{-1}$ $\left(\mathrm{N}_{2}\right)$. The column temperature was set to increase from $160{ }^{\circ} \mathrm{C}$ to $200{ }^{\circ} \mathrm{C}$ at a rate of $40{ }^{\circ} \mathrm{C} \mathrm{min}-1$, and then at $220{ }^{\circ} \mathrm{C}$ at $5{ }^{\circ} \mathrm{C} \mathrm{min}-1 ; 0,5 \mu \mathrm{L}$ of the sample volume was injected, using an autosampler, for each GC-FPD run. The limit detection was $2 \mathrm{ppm}$.

\section{RESULTS AND DISCUSSION}

\subsection{Effect of the nature of support}

Characterization results by the BET method and isoelectric points by Electrophoretic Migration measurements of the different supports studied are shown in Table 1.

It is clear that the $\mathrm{C}$ have a larger specific area, it is also noted that $\gamma-\mathrm{Al}_{2} \mathrm{O}_{3}$ is the support that has the smallest pore volume, also $\gamma-\mathrm{Al}_{2} \mathrm{O}_{3}$ has the highest isoelectric point of the supports studied (8.7), $\mathrm{SiO}_{2}$ and $\mathrm{C}_{\text {act }}$ have very similar isoelectric points, 3.2 and 4.0 respectively; It should be noted that this causes that the supports studied having negative charge at $\mathrm{pH}>$ IEP. Note that for the case of alumina to $\mathrm{pH}<8.7$, will have a net positive charge; $\mathrm{C}_{\text {act }}$ and $\mathrm{SiO}_{2}$ may have net positive charge only at very acidic $\mathrm{pH}$.

Table 1: Specific BET area, IEP and adsorption capacities of Pyridine per grams of different supports studied.

\begin{tabular}{|c|c|c|c|c|}
\hline Support & $\begin{array}{c}\text { Specific } \\
\text { area } \\
\left(\mathbf{m}^{2} \mathbf{g}^{-1}\right)\end{array}$ & $\begin{array}{c}\text { Pore } \\
\text { volume } \\
\left(\mathbf{c m}^{\mathbf{3}} \mathbf{g}^{-1}\right)\end{array}$ & $\begin{array}{c}\text { IEP } \\
(\mathbf{p H})\end{array}$ & $\begin{array}{c}\text { Adsorption } \\
\text { Capacity } \\
(\mathbf{m g} \text { Pyridine } \\
\left.\text { (g Ads. })^{-1}\right)\end{array}$ \\
\hline${\mathbf{\gamma}-\mathbf{A l}_{\mathbf{2}} \mathbf{O}_{\mathbf{3}}}^{\mathbf{1}}$ & 213 & 0.49 & 8.7 & 22.1 \\
\hline $\mathbf{S i O}_{2}$ & 195 & 0.80 & 3.2 & 0.0 \\
\hline $\begin{array}{c}\text { Activated } \\
\text { Carbon }\end{array}$ & 818 & 0.89 & 4.0 & 3.6 \\
\hline
\end{tabular}

By integrating the area under the adsorption curves, the saturation adsorption capacities can be estimated. The Adsorption capacities of pyridine for supports studied are shown also in Table 1. Firstly, it is clear that there is no relationship between the specific areas of the supports studied and its adsorption capacity.

The results shown that within the supports studied, $\gamma-\mathrm{Al}_{2} \mathrm{O}_{3}$ is the only support having a substantial capacity to adsorb pyridine between the studied support (22.1 $\mathrm{mg}$ ( $\mathrm{g}$ of support $)^{-1}$ ); this is mainly due to that the feed used has a $\mathrm{pH}$ near 7.0, less than the IEP of alumina (8.7), at $\mathrm{pH} 7.0$ the alumina possesses a net positive charge or electron deficient so that the pyridine adsorption is favored, because pyridine is a Lewis base; on the other hand, silica and $\mathrm{C}$ have a minor IEP ( 3.2 and 4.0, respectively) and at $\mathrm{pH} 7.0$ both supports have negative net charge or excessive electrons pairs, preventing the adsorption of the pyridine as Lewis base. This behavior can be seen more clearly in Fig.1, in which the dependence of the adsorption capacity of the materials studied with its IEP is observed, clearly shows a decrease in the adsorption capacity as the IEP of the support is less than 7.0; in the case of $\mathrm{C}_{\text {act }}$ this has a slight adsorption capacity which can be explained by the presence of a surface group that may have a $\mathrm{pH} 7.0$ acidic property and can be protonated at the $\mathrm{pH}$; or the large specific surface area of this material.

\subsection{Effect of the addition of $\mathrm{Ni}$}

Characterization results by the BET method, isoelectric points, zero point change (ZPC) and fraction of covered surface by metals $\left(\mathrm{X}_{\mathrm{M}}\right)$ by Electrophoretic migration measurements, of $\mathrm{Ni}(\mathrm{X} \%)$ supported on $\gamma-\mathrm{Al}_{2} \mathrm{O}_{3}$ adsorbent are shown in Table 2. First, we observed a very slight decrease in the specific area increasing metal content, at higher metal content studied $(6 \%$ $\mathrm{Ni}$ ) the decreasing is close to $2 \%$ of the initial area of the support, so in reality there isn't a decrease in specific area with the metal content; probably because the metal is well dispersed on the support surface. Fig. 2 shows measurement of zeta potential (ZP) with the $\mathrm{pH}$ of the solution samples $\gamma-\mathrm{Al}_{2} \mathrm{O}_{3}, \mathrm{NiO}, \mathrm{Ni}(\mathrm{x} \%) /$ $\gamma-\mathrm{Al}_{2} \mathrm{O}_{3}$, to determine the isoelectric points (IEP) of $\gamma-\mathrm{Al}_{2} \mathrm{O}_{3}$ and $\mathrm{NiO}$, and the zero point charge (ZPC) of the adsorbents $\mathrm{Ni}(\mathrm{x} \%) / \gamma-\mathrm{Al}_{2} \mathrm{O}_{3}$, which are shown in Table 2.

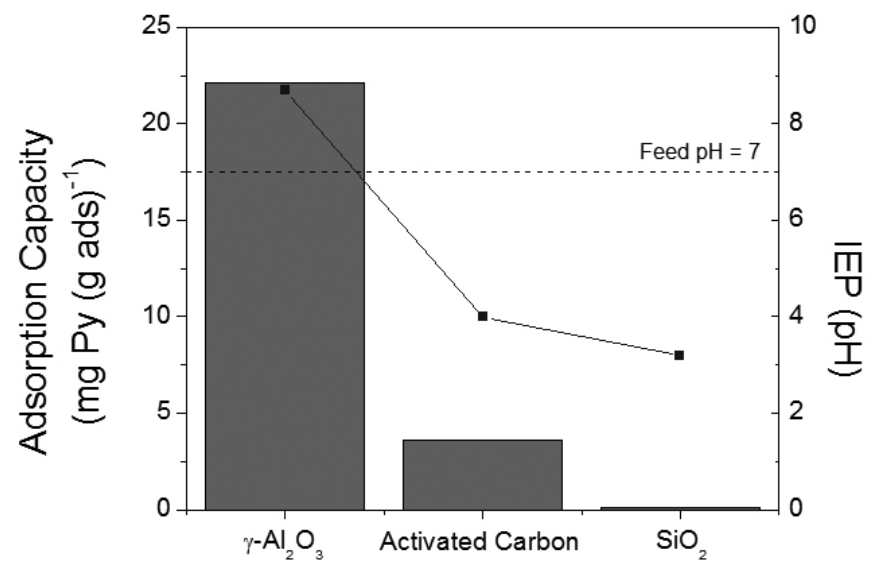

Fig.1 Adsorption capacities of Pyridine (bars) and IEP (dots) for studied supports

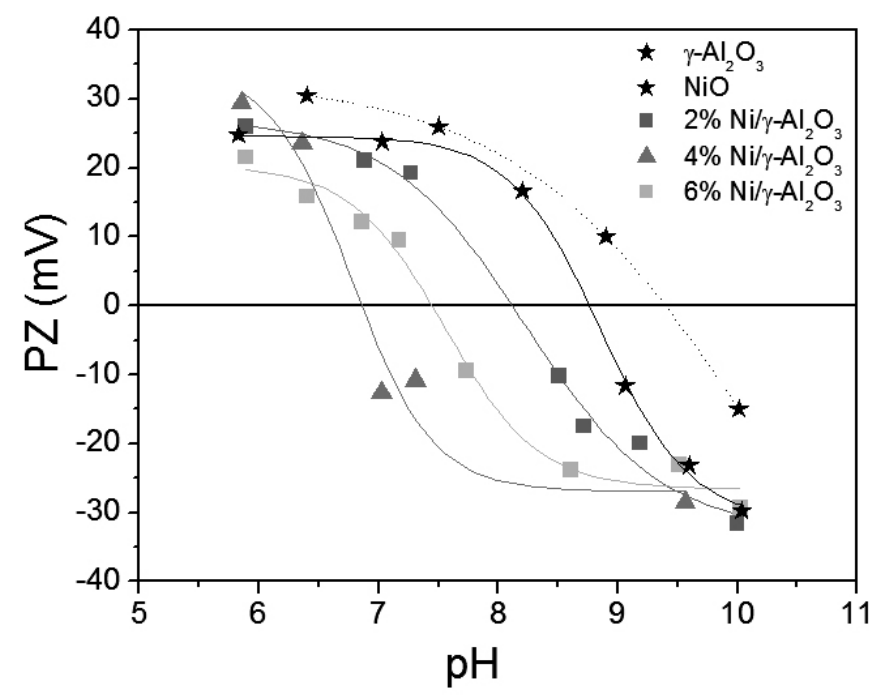

Fig. 2 Electrophoretic migration measurement of $\mathrm{Ni}(\mathrm{x}) / \gamma-\mathrm{Al}_{2} \mathrm{O}_{3}$ adsorbents

In Table 2 we can observe that by impregnating alumina with Ni decreases the ZPC with the metallic content from the IEP of the alumina (8.7) to the ZPC of the adsorbent $4 \% \mathrm{Ni} / \gamma-\mathrm{Al}_{2} \mathrm{O}_{3}(6.8)$; this decrease is due to the formation of species with lower IEP; in this case the formation of aluminate, which has an IEP of 2.7. Until content near to $4 \%$, the $\mathrm{Ni}$ would not form $\mathrm{NiO}$ species because then the ZPC should be greater than the IEP of alumina. It is also noted that $\mathrm{X}_{\mathrm{M}}$ increased by forming aluminate dispersed on the alumina surface, reached a value of 0.33 to $4 \%$ of $\mathrm{Ni}$.

At higher contents $(6 \% \mathrm{Ni})$, the ZPC increases from the value of $6.8(4 \%)$ to 7.5 for $6 \% \mathrm{Ni} / \gamma-\mathrm{Al}_{2} \mathrm{O}_{3}$, due to a higher content begins to form $\mathrm{NiO}$ (IEP 9.4) on the aluminate; for this adsorbent is not possible to calculate the $\mathrm{X}_{\mathrm{M}}$ because we have 3 species present ${ }^{28}$.

In Table 2, finally the values for pyridine adsorption capacity are shown, expressed in $\mathrm{mg}$ of pyridine adsorbed per gram of adsorbent, obtained from the area under the adsorption curve. It's clearly shown that the adsorption capacity decreases with the metal content; from $22.1 \mathrm{mg} \mathrm{g}^{-1}$ (for $\gamma-\mathrm{Al}_{2} \mathrm{O}_{3}$ ) to $14.6 \mathrm{mg} \mathrm{g}^{-1}$, when the nickel content is $4 \%$, the adsorption capacity then increases to 16.1 $\mathrm{mg} \mathrm{g}^{-1}$, when the content reaches $6 \%$.

For this results, we see that there is a direct correlation between the presences of $\mathrm{NiO}$ on the surface and adsorption capacity, also the presence of 
aluminate decreases the adsorption capacity of the material.

Furthermore, there is a relationship between the ZCP of adsorbent with adsorption capacity, this relationship is observed better in Fig. 3.

Table 2: Isoelectric point (IEP), zero point of charge (ZPC), Fraction of covered surface by metals $\left(\mathrm{X}_{\mathrm{M}}\right)$, Specific areas measured by BET and adsorption capacities of $\mathrm{Ni}(\mathrm{X} \%)$ supported on $\gamma-\mathrm{Al}_{2} \mathrm{O}_{3}$.

\begin{tabular}{|c|c|c|c|c|c|c|}
\hline Sample & $\begin{array}{c}\text { Nominal } \\
\text { Metal } \\
\text { content } \\
(\%)\end{array}$ & $\begin{array}{c}\text { Specific } \\
\text { area } \\
\left(\mathrm{m}^{2} \mathrm{~g}^{-1}\right)\end{array}$ & IEP & ZPC & $\mathbf{X}_{\mathrm{M}}$ & $\begin{array}{l}\text { Adsorption } \\
\text { Capacity } \\
\text { (mg } \\
\text { Pyridine (g } \\
\left.\text { Ads. })^{-1}\right)\end{array}$ \\
\hline$\gamma-\mathrm{Al}_{2} \mathrm{O}_{3}$ & -- & 213 & 8.7 & -- & 0.00 & 22.1 \\
\hline $\begin{array}{l}\mathrm{Ni}(2) / \gamma- \\
\mathrm{Al}_{2} \mathrm{O}_{3}\end{array}$ & 2 & 210 & -- & 8.1 & 0.10 & 16.0 \\
\hline $\begin{array}{l}\mathrm{Ni}(4) / \gamma- \\
\mathrm{Al}_{2} \mathrm{O}_{3}\end{array}$ & 4 & 209 & -- & 6.8 & 0.33 & 14.6 \\
\hline $\begin{array}{c}\mathrm{Ni}(6) / \gamma- \\
\mathrm{Al}_{2} \mathrm{O}_{3}\end{array}$ & 6 & 208 & -- & 7.5 & -- & 16.1 \\
\hline $\mathrm{NiO}$ & & & 9.4 & & & \\
\hline $\mathrm{NiAl}_{2} \mathrm{O}_{4}$ & & & $2.7^{(*)}$ & & & \\
\hline
\end{tabular}

(*) Taken from reference 28

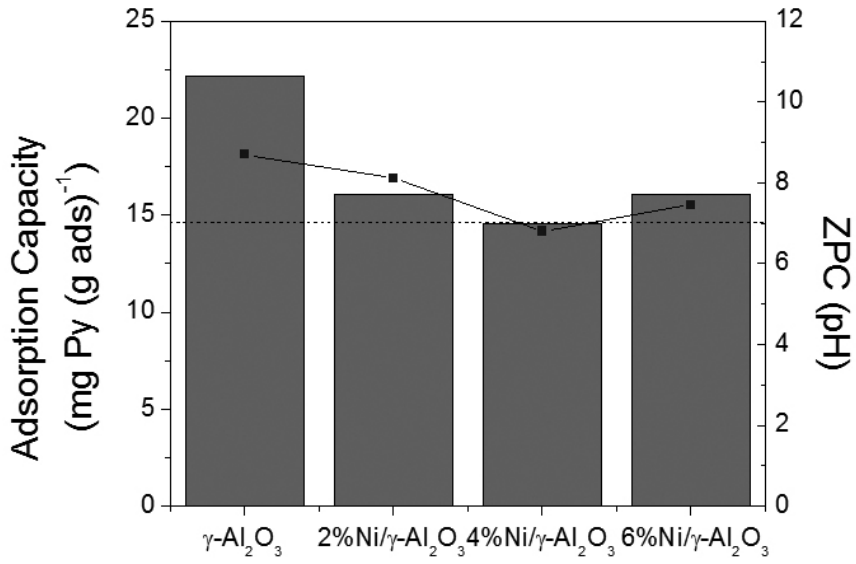

Fig. 3 Adsorption capacity of Pyridine (bars) and ZPC (dots) of Ni supported on alumina adsorbents

In Fig. 3, if we observe the ZPC of adsorbents and IEP of alumina; there is a direct relationship between the $\mathrm{ZPC}$ and the adsorption capacity; when the ZPC of adsorbent decreases, the adsorbent loses surface positive charge, for example to $4 \% \mathrm{Ni} / \gamma-\mathrm{Al}_{2} \mathrm{O}_{3}$ adsorbent, the $\mathrm{pH}$ of feed (near to 7.0 ) is slightly higher than the ZPC of material (6.8), losing in this case the property of acid Lewis that the adsorbent will possessed at less content or even the support and losing adsorption capacity due to the Lewis base pyridine property.

For $6 \% \mathrm{Ni} / \gamma-\mathrm{Al}_{2} \mathrm{O}_{3}$ adsorbent, the adsorption capacity increases again; because also increases the $\mathrm{ZPC}$ to 7.5 ; due to the presence of $\mathrm{NiO}$ surface, while the difference between the $\mathrm{pH}$ of the feed and the $\mathrm{ZPC}$ of adsorbent is minimal in this case we can also have the factor of adsorption via $\pi$-complexation of Ni(II).

Additionally, we have carried out the adsorption of quinoline with the same adsorbents used in this work, it's interesting that despite the molecular size of the quinoline, better adsorption capacities are observed for the three adsorbents, this allows us to deduce that adsorption by $\pi$-complexation could be used to the treatment of refractory molecules, this results will be analyzed in a future work.

\section{CONCLUSIONS}

The study of the adsorption capacity for the three different supports shows that not exists a direct relationship between the BET area of the support and its adsorption capacity, however and important factor correspond to the IEP of the support, being $\gamma-\mathrm{Al}_{2} \mathrm{O}_{3}$ who possesses the highest adsorption capacity, this is because $\gamma-\mathrm{Al}_{2} \mathrm{O}_{3}$ have a positive net charge on his surface favoring the adsorption of pyridine which acts as a Lewis base. The incorporation of $\mathrm{Ni}$ on the support generates a decrease in the adsorption capacity of the support, which depends on the ZPC, associated with the presence of aluminates and $\mathrm{NiO}$ on the surface of the support.

\section{ACKNOWLEDGMENT}

The authors are grateful to the Chilean government for financial support from CONICYT through FONDECYT grant 1140808.

\section{REFERENCES}

1. J.B. Speight, Chemistry and Technology of Petroleum, New York (1998)

2. S. Shin, K. Sakanishi, I. Mochida, D.A. Grudoski, J.H. Shinn. Energy \& Fuels 14, 539-544 (2000)

3. G.C. Laredo, S. Leyva, R. Alvarez, M.T. Mares, J. Castillo, J.L. Cano, Fuel 81, 1341-1350 (2002)

4. P.Grange, Catal. Rev.-Sci.Eng. 21, 135-181 (1980).

5. A.K. Mathur, C.B. Majumder, S. Chatterjee, J. Hazard. Mater. 157, 335 343 (2008)

6. K.V. Padoley, A.S. Rajvaidya, T.V. Subbarao, Biores. Technol. 97, 1225 1236 (2006)

7. L. Qiao, J. Wang, J. Hazard. Mater. 176, 220-225 (2010)

8. H. Zhao, S. Xu, J. Zhong, X. Bao, Catal. Today 93-95, 857-861 (2004).

9. R. Andreozzi, A. Insola, V. Caprio, M.G. D'Amore, Water Res. 25, 655659 (1991).

10. M.K. Mandal, P.K. Bhattacharya, J. Membrane Sci. 286, 115-124 (2006)

11. M.E. Essington, Environ. Geol. Water Sci. 19, 83-89 (1992).

12. D.H. Lataye, I.M. Mishra, I.D. Mall, J. Hazard. Mater. 154, 858-870 (2008)

13. D. Mohan, K.P. Singh, S. Sinha, D. Gosh, Carbon 43, 1680-1693 (2005)

14. J. Ren, J. Wang, C. Huo, X. Wen, Z. Cao, S. Yuan, Surf. Sci. 601, 1599 1607 (2007)

15. P. Baeza, G. Aguila, F. Gracia, P. Araya, Catal. Commun. 9, 751-755 (2008).

16. P. Baeza, G. Aguila, G. Vargas, J. Ojeda, P. Araya, Appl. Catal. B 111,133$140(2012)$

17. A.J.Hernandez-Maldonado, R.T. Yang, AIChE Journal 50(4), 791-801 (2004)

18. F. Aparicio, E. Camú, M. Villarroel, N. Escalona, P. Baeza, J. Chil. Chem. Soc. 58, 2057-2060 (2013).

19. O. Hamdaoui, E. Naffrechoux. J. Hazard Mater. 147, 381-394 (2007)

20. A.K. Bajpai, M. Rajpoot, D.D. Mishra, J. Colloid Interface Sci. 187, 96 104 (1997)

21. C. Huang, J. Colloid Interface Sci. 53,178-186 (1975)

22. E. Baumgarten, U. Kirchhausen-Dusing, J. Colloid Interface Sci. 194, 1-9 (1997)

23. T. Tranior, G. Brown Jr., G. Parks, J. Colloid Interface Sci. 231, 359-372 (2000)

24. J. Kwon, J. Moon, Y. Bae, D. Lee, H. Sohn, C. Lee. ChemSusChem. 1, $307-309$ (2008)

25. A. Koriakin, K. Muruganandam, C. Lee. Chem. Eng. J. 162, 649-655 (2010)

26. J.-P. Bellat, I. Bezverkhyy, G. Weber, S. Royer, R. Averlant, J.-M. Giraudon and J.-F. Lamonier, J. Hazard. Mater. 300 711-717 (2015)

27. H. Yamada, D. S. Dao, J. Fujiki and K. Yogo, Sep. Sci. Technol. 50, 2948 2953 (2015) Department of Chemical and Biomolecular Engineering, Yonsei University, 262 SeongSanno, Seodaemun-gu, Seoul 120-749, South Korea Received 6 April 2010, Revised 9 June 2010, Accepted 9 June 2010, Available online 17 June 2010

28. F.J. Gil Llambias, A.M. Escudey, J. Santos-Blanco, J. Catal. 83, 225-228 (1983). 